\title{
Predictors of sleeping under cost-free mosquito bed nets among children under-five years in Mbarara, Uganda: a household survey
}

\author{
Maureen Andinda, ${ }^{1}$ Edgar Mulogo, ${ }^{2}$ Eleanor Turyakira, ${ }^{2}$ Vincent Batwala ${ }^{2,3}$
}

1. School of Health Sciences, Mountains of the Moon University, P.O. Box 837, Fort Portal, Uganda

2. Department of Community Health, Mbarara University of Science \& Technology P. O. Box 1410, Mbarara, Uganda.

3. Directorate of Research and Graduate Training, Mbarara University of Science \& Technology P. O. Box 1410, Mbarara, Uganda.

\section{Email addresses:}

MA: kakurusan@gmail.com, EM: emulogo2000@gmail.com, ET: eturyakira@must.ac.ug, vB: vbatwala@must.ac.ug

\begin{abstract}
Background: In 2010, Uganda Malaria Control Programme distributed cost-free mosquito bed nets to households with children under-five years and pregnant women in selected sub-counties. We assessed the factors associated with sleeping under costfree mosquito nets among children under-five years in Nyakayojo sub-county, Mbarara District, Uganda.

Methods: 381 households with at least a child under-five years and benefited from cost-free bed nets in Nyakayojo were randomly selected. Caregivers of children were interviewed using a questionnaire.

Results: $74 \%$ children slept under bed nets a night before the study. Children from households with $\geq 2$ nets [aOR $=1.75 ; 95 \%$ CI: $1.09-2.81, \mathrm{p}=0.02]$, female caregiver $[\mathrm{aOR}=2.11 ; 95 \% \mathrm{CI}: 1.16-3.79, \mathrm{p}=0.01]$ and children from households that did not face problems (skin irritation, torn nets, suffocation, night sweating, nasal congestion and candle fire) when sleeping under bed nets $[\mathrm{aOR}=1.81 ; 95 \%$ CI: 1.10-2.98, $\mathrm{p}=0.02]$ were more likely to use nets. Main reason for not sleeping under a net was damage to the net $(47.1 \%)$.
\end{abstract}

Conclusion: The proportion of children sleeping under nets was comparable to MDG target. Improvements in use of mosquito nets by children can be achieved through increasing number of nets in a household.

Keywords: Cost-free, mosquito nets, use, under-five, Uganda.

DOI: https://dx.doi.org/10.4314/ahs.v19i1.7

Cite as: Andinda M, Mulogo E, Turyakira E, Batwala V. Predictors of sleeping under cost-free mosquito bed nets among cbildren under-five years in Mbarara, Uganda: a household survey. Afri Health Sci. 2019;19(1): 1353-1360. https:// dx.doi.org/10.4314/abs.v19i1.7

\section{Background}

Malaria poses a threat to the health of the populations, especially in tropical countries ${ }^{1}$. Globally, 149 - 303 million malaria cases were reported in 2015 and most of these

\section{Corresponding author:}

Vincent Batwala,

Directorate of Research and Graduate Training,

Mbarara University of Science \& Technology;

P. O. Box 1410, Mbarara, Uganda.

Email:vbatwala@must.ac.ug cases occurred in African children ${ }^{2}$. In Uganda, hospital records suggest that malaria is responsible for 30 to $50 \%$ of out-patient visits, 15 to $20 \%$ of admissions, and 9 to $14 \%$ of in-patient deaths. Moreover the Uganda malaria indicator survey of 2014/15 reported that the overall prevalence among children aged 0-59 months decreased from $42 \%$ in 2009 to $19 \%$ in 2014 . However, malaria still has a great impact on economic development from the individual to the national level through direct costs in form of treatment, treatment seeking and funeral expenses, expenditure on treatment and prevention ${ }^{3}$. 
Insecticide treated nets (ITNs) are amongst the effective tools for reducing malaria transmission and related morbidity and mortality. However, utilization rates among some African communities have not improved ${ }^{4}$. Although the proportion of Ugandan children under-five years of age who sleep under mosquito bed nets was reported to have increased from $8 \%$ in $2001^{5}$ to $74 \%$ in $2014^{6}$, this improvement still fell short of the Millennium Development Goal (MDG) target of $80 \%{ }^{7}$.

The goal of malaria control in Uganda is to prevent morbidity and mortality as well as to minimize social effects and economic losses attributable to malaria. In order to achieve this goal, the Uganda Malaria Control Programme (UMCP) endeavors to implement a package of effective and appropriate interventions, one of which is the use of long lasting insecticide-treated nets (LLITNs) ${ }^{8}$. Thus in 2010, the UMCP distributed 7.2 million LLITNs to various communities in the country targeting households with pregnant women and children under-five years. However, bed net use after the free distribution exercise has not been assessed. This study therefore assessed the use of the cost free distributed mosquito bed nets among children below five years of age who were residents of Nyakayojo sub-county in Mbarara district of Uganda.

\section{Methodology \\ Study design and setting}

This was a household cross-sectional study, carried out in Nyakayojo sub-county of Mbarara district in 2012. Nyakayojo is located about $296 \mathrm{~km}$ SouthWest of the capital city Kampala. It is composed of six parishes and 61 villages, with an estimated population of 29,396. The subcounty is ethnically heterogeneous but the Banyankole constitute the dominant inhabitants. The main economic activity is semi-intensive agriculture focusing on banana (plantain, the staple food locally known as Ebitookye) production.

Nyakayojo sub-county was among those communities that benefited from the cost free bed net distribution in 2010, receiving a total of 11,363 nets. In addition to households with pregnant women and children under-five years of age; Community Health Workers (in Uganda known as Village Health Teams or VHTs), and local leaders at the village levels also benefited from the bed nets distribution exercise. The distribution was led by VHTs at designated points. Most bed nets were square. All nets were white and had a distinct emblem as an identifier for the government of Uganda distributed nets. During distribution, instructions were given about hanging, cleaning and general care plus the benefits of regularly sleeping under the bed nets.

\section{Sample size estimation, sampling procedure and data collection}

The sample size of 381 children under five years was estimated using a standard formula ${ }^{9}$, assuming an acceptable error of $5 \%, 34.2 \%{ }^{10}$ of children sleeping under mosquito bed nets and adjusted by $10 \%$ for non-response. Two (2) parishes (Katojo and Rukindo) out of the 6were randomly selected from which participants were enrolled. The list of households in the 2 parishes was obtained from Nyakayojo sub-county headquarters and was used as the sampling frame. Thereafter, 381 households were randomly selected. Each parish contributed to the sample in proportionate to the size of its population. Consenting caregivers (one care giver per household) were interviewed at their homes using a semi-structured questionnaire. If a household had more than one child below five years of age, only one (index child) was selected randomly and was the focus of the interview.

\section{Ethical considerations}

Ethical approval was obtained from the Faculty of Medicine Research Committee of Mbarara University of Science and Technology; and MUST Research Ethics Committee. Written informed consent was obtained from all study respondents (caregivers of children) at the time of interview in their homes.

\section{Data analysis}

Data was analysed using STATA version 12 (STATA Corp. LP, College Station, Texas, USA). Bivariate analysis with the chi-squared test was used to compare proportions. Probability values ( $\mathrm{p}$-values) were set at 0.05 level of significance and Confidence Intervals (CIs) were calculated at the $95 \%$ level. To identify independent predictors of sleeping under the cost free bed nets, variables found significant in the bivariate analysis ( $p$-value $\leq 0.05$ ) were fitted into a stepwise multivariate logistic regression model assuming variable categories were mutually exclu- 
sive and exhaustive; and there was no linear relationship between the dependent and independent variables. The model goodness-of-fit was tested using the "lfit" command.

\section{Results}

Socio-demographic and economic characteristics of respondents

381 households with children under-five years of age and at least one bed net were visited in September 2012. The mean age of respondents in years was 32.6 ( $\pm 12.3 \mathrm{SD})$. Some $65(17.06 \%)$ respondents were from female-headed households. Female respondents constituted 319 $(83.73 \%)$. Some households $245(64.30 \%)$ were living in semi-permanent houses and 261(68.50\%) were living in houses that they owned. Only 151 (39.63\%) of household heads and 125 (32.81\%) of care givers had attained secondary education. Additional socio-demographic and economic characteristics are shown in Table 1.

Table 1: Socio-demographic and economic characteristics of study participants $(\mathrm{N}=381)$

$\begin{array}{ll}\text { Characteristic } & \text { n (\%) }\end{array}$

Median household size

Mean number of children below five years in household

Median birth order of index child

Religion of household head

Catholic

Other

Marital status of caregiver

Single

Married/ living with partner

Divorced/ separated

Widowed

Car ownership in household

Motorcycle in household

Bicycle in household

Electricity in household

Occupation of household head

Not gainfully employed

Employed
5

$1.60[1.52-1.69]^{*}$

2

$259(68.0)$

$122(32.0)$

11(2.9)

$297(78.0)$

$47(12.3)$

$26(6.8)$

$11(3.0)$

$65(17.1)$

167 (43.8)

$39(10.2)$

$118(31.0)$

$263(69.1)$

*95\% Confidence Interval 


\section{Bed net use}

Majority of the households $229(60.10 \%)$ owned more than one bed net. Some 165 (43.31\%) households bought at least a net in addition to those distributed by the Malaria Control Programme. Other sources of nets includ- ed those distributed at the health centers $4(1.05 \%)$ by various projects implemented within the health facility catchment area, and donation by non-governmental organizations $9(2.36 \%)$. Two hundred forty six households $(64.57 \%)$ had rectangular nets while $341(89.50 \%)$ had white nets (Table 2).

Table 2: Bed net use

\begin{tabular}{ll}
\hline Variable & $\mathbf{n}(\mathbf{\%})$ \\
\hline Median number of nets in a household & 2 \\
Mean cost of a bed net (US\$) & 3.2 \\
Child slept under bed net the night before the survey & $281(73.75)$ \\
Child regularly sleeps under bed net daily & $278(72.97)$ \\
Rectangular shape mosquito bed net & $335(87.93)$ \\
Circular mosquito bed net & $46(12.07)$ \\
\hline
\end{tabular}

\section{Predictors of using free bed nets}

In bivariate analysis (Table 3), four variables: gender of caregiver [Odds Ratio $(\mathrm{OR})=2.02$; 95\%CI: 1.14-3.58, $\mathrm{p}=0.02]$; occupation of househod head $[\mathrm{OR}=1.84$; 95\% CI: 1.07-3.14, $\mathrm{p}=0.03$ ]; number of bed nets in the household [OR=1.66; 95\%CI: 1.05-2.63, $\mathrm{p}=0.03$ ]; and not facing problems using nets in household $[\mathrm{OR}=1.93$; 95\%CI: 1.18-3.13, $\mathrm{p}=0.01$ ] were associated with bed net use. These variables were thus retained and fitted into the multivariate model. In the multivariate analysis (Table 4), not facing problems in using nets [adjusted Odds Ratio $(\mathrm{aOR})=1.81$; 95\%CI: 1.10-2.98, $\mathrm{p}=0.02]$; female caregiver $[\mathrm{aOR}=2.11$; 95\%CI: 1.16-3.79, $\mathrm{p}=0.01]$; and having two or more nets in household [aOR $=1.75$; 95\%CI: 1.09-2.81, $\mathrm{p}=0.02]$ were independent predictors of sleeping under free mosquito bed nets, with the model goodness-of-fit results indicating Chi-square $(\mathrm{df}=11, \mathrm{n}=381, \mathrm{p}=0.116)=$ 16.7. The reported problems hindering the utilization of mosquito bed nets are shown in table 5 . 
Table 3: Factors associated with cost free bed net use (bivariate analysis)

\begin{tabular}{|c|c|c|c|c|}
\hline \multirow[b]{2}{*}{ Variable } & \multicolumn{2}{|c|}{ Slept under bed net } & \multirow[t]{2}{*}{ OR $[95 \% \mathrm{CI}]$} & \multirow[t]{2}{*}{$p$-value } \\
\hline & $\begin{array}{l}\text { No } \\
\mathrm{n}(\%)\end{array}$ & $\begin{array}{l}\text { Yes } \\
\mathrm{n}(\%)\end{array}$ & & \\
\hline \multicolumn{5}{|l|}{ Sex of index child } \\
\hline Male & $45(24.19)$ & $141(75.81)$ & & \\
\hline Female & $55(28.21)$ & $140(71.79)$ & $0.81[0.51-1.29]$ & 0.37 \\
\hline \multicolumn{5}{|l|}{ Sex of household head } \\
\hline Male & $84(26.58)$ & $232(73.42)$ & $1.11[0.59-2.06]$ & 0.74 \\
\hline Female & $16(24.62)$ & $49(17.44)$ & & \\
\hline \multicolumn{5}{|l|}{ Sex of caregiver } \\
\hline Male & $24(38.71)$ & $38(61.29)$ & & \\
\hline Female & $76(23.82)$ & $243(76.18)$ & $2.02[1.14-3.58]$ & $0.02 *$ \\
\hline \multicolumn{5}{|l|}{ Age of index child in months } \\
\hline $1-12$ months & $26(25.49)$ & $76(74.51)$ & $0.95[0.56-1.59]$ & 0.84 \\
\hline $13-60$ months & $74(26.52)$ & $205(73.48)$ & & \\
\hline \multicolumn{5}{|l|}{ Birth order of index child } \\
\hline $1^{\mathrm{st}}-2^{\mathrm{nd}}$ & $58(29.74)$ & $137(70.26)$ & & \\
\hline $3^{\text {rd }}$ and above & $42(22.58)$ & $144(77.42)$ & $1.45[0.92-2.30]$ & 0.11 \\
\hline \multicolumn{5}{|l|}{ Marital status of caregiver } \\
\hline Married/living with partner & $77(25.93)$ & $220(74.07)$ & $1.05[0.62-1.86]$ & 0.79 \\
\hline Other & $23(27.38)$ & $61(72.62)$ & & \\
\hline \multicolumn{5}{|l|}{ Occupation of household head } \\
\hline Employed & $78(29.66)$ & $185(70.34)$ & & \\
\hline Not gainfully employed & $22(18.64)$ & $96(81.36)$ & $1.84[1.07-3.14]$ & $0.03 *$ \\
\hline \multicolumn{5}{|l|}{$\begin{array}{l}\text { Highest level of education attained } \\
\text { by caregiver }\end{array}$} \\
\hline Secondary/tertiary & $40(32.00)$ & $85(68.00)$ & & \\
\hline Never/primary & $60(23.44)$ & $196(76.56)$ & $1.54[0.96-2.47]$ & 0.07 \\
\hline \multicolumn{5}{|l|}{$\begin{array}{l}\text { Highest level of education attained } \\
\text { by household head }\end{array}$} \\
\hline Secondary/tertiary & $47(31.13)$ & $104(68.87)$ & & \\
\hline Never/ primary & $53(23.04)$ & $177(76.96)$ & $1.51[0.95-2.39]$ & 0.08 \\
\hline $\begin{array}{l}\text { One-two children below five years in } \\
\text { household }\end{array}$ & $87(25.89)$ & $249(74.11)$ & $0.86[0.43-1.71]$ & 0.66 \\
\hline $\begin{array}{l}\text { Number of people in a household } \\
(\leq 5)\end{array}$ & $66(28.45)$ & $166(71.55)$ & $1.34[0.83-2.17]$ & 0.22 \\
\hline \multicolumn{5}{|l|}{ Number of bed nets in a household } \\
\hline 1 net & $49(32.24)$ & $103(67.76)$ & & \\
\hline 2 and above & $51(22.27)$ & $178(77.73)$ & $1.66[1.05-2.63]$ & $0.03 *$ \\
\hline \multicolumn{5}{|l|}{ Shape of net the index child is using } \\
\hline Rectangular & $87(25.97)$ & $248(74.03)$ & & \\
\hline Circular & $13(28.26)$ & $33(71.74)$ & $0.89[0.45-1.77]$ & 0.74 \\
\hline Face problems using nets in & & & & \\
\hline household & $61(22.43)$ & $211(77.57)$ & $1.93[1.18-3.13]$ & $0.01 *$ \\
\hline No & $39(35.78)$ & $70(64.22)$ & & \\
\hline Yes & & & & \\
\hline
\end{tabular}


Table 4: Factors associated with cost free bed net use (multivariate analysis)

\begin{tabular}{lll}
\hline Variable & aOR $[95 \% \mathrm{CI}]$ & $p$-value \\
\hline Do not face problems in using bed nets in the household & $1.81[1.10-2.98]$ & $0.02 *$ \\
Female caregiver & $2.11[1.16-3.79]$ & $0.01 *$ \\
Head of household unemployed & $0.89[0.78-1.00]$ & 0.06 \\
Having 2 or more nets in household & $1.75[1.09-2.81]$ & $0.02 *$ \\
\hline
\end{tabular}

*Statistically significant; aOR = adjusted Odds Ratio; $\mathrm{CI}=$ confidence interval

Table 5: Problems faced in relation to bed net use.

$\begin{array}{ll}\text { Problem faced } & \text { Frequency }(\%)^{*}\end{array}$

Skin irritation

Suffocation/nasal congestion

Sweating at night

Candle fire

They get torn and they get dirty
$42(38.53)$

$62(56.9)$

21(19.26)

$4(3.67)$

$5(4.59)$

* percentages add up to more than 100, respondents were allowed to mention multiple problems

\section{Discussion}

The current study shows that having two or more nets in household; not facing problems in using bed nets; and female caregiver were independent predictors of sleeping under freely distributed bed nets by children under-five years of age.

Having two or more nets points to availability of these commodities at the household level and thus enabling children to access them. This finding is in agreement with earlier studies done in Uganda ${ }^{11,12,13}$ and those carried out elsewhere ${ }^{11,14}$. This implies that increasing availability of bed nets with in households may enhance utilization among children. A study in Nigeria six months after a free mosquito distribution in a mass campaign also indicated that a ratio of one net to two persons in a household enhanced utilization ${ }^{15}$. In our study the median household size was five people. This clearly shows that if a household had only one bed net, it could not match the above ratio ( 1 bed net: 2 people) and would compromise utilization especially among the under five children who need them most. Therefore, the current study confirms that having two or more nets in a household is critical to utilization by children less than five years of age. 
The finding that female caregivers were more likely to report that their children slept under a mosquito net was a likely reflection that they know more about child care than the males in Africa. Our finding mirrors an earlier Tanzania gender-based study that reported that females were generally more willing to pay for a bed net at the lowest price compared to the males ${ }^{16}$, and were reported to have their children sleeping under a bed net.

Facing problems in relation to bed nets in households hinders utilization as reported here. This finding was also reported in SouthEast Asia ${ }^{17}$, and elsewhere ${ }^{18}$. This implies that people may fail to use an intervention once they are uncomfortable with it in one way or another. There is need for regular monitoring of interventions following operationalization to quickly identify and devise alternative implementation pathways. Respondents who cited that their households were facing problems in relation to bed nets were less likely to have their children sleep under bed nets. This is in agreement with a qualitative study in Nigeria ${ }^{19}$ where problems like fear of candle fires, skin irritation when the net gets in contact with the body and difficulty in hanging and folding up in the morning as barriers to bed net use. Increase in temperature when the net is drawn at night resulting into sweating was earlier on reported in $\mathrm{China}^{20}$. In Nigeria ${ }^{21}$ chemicals used to treat the nets were thought to be harmful to adults, children and pregnant women especially affecting breathing a fact that is also reported here as suffocation. As expected, adult child caregivers make decisions to protect their children from adverse reactions emanating from the use of nets. Finding solutions to some of these challenges will help in improving bed net use especially among children who are highly at risk of malaria.

\section{Conclusion}

The proportion of children sleeping under cost free mosquito nets is comparable to the MDG set target. Further improvements in utilization by the under five children can be achieved through increasing the number of mosquito nets in a household.

\section{List of abbreviations}

ITNs: Insecticide Treated Nets

ITN: Insecticide treated net

MDG: Millennium Development Goal
UMCP: Uganda Malaria Control Programme

LLITNs: Long Lasting Insecticide-treated Nets

VHTs: Village Health Teams

\section{Ethics and consent to participate}

Ethical approval was sought from the Faculty of Medicine Research and Ethics Committee; and the Institutional Review Committee of Mbarara University of Science and Technology. All participants consented in writing at the time of interview in their homes.

\section{Competing interests}

Authors declare that there is no conflict of interest in this study

\section{Authors' contributions}

All authors conceived and designed the study; AM and VB collected, analysed, interpreted the data and drafted the manuscript; EM critically revised the manuscript. All authors read and approved the final manuscript.

\section{Acknowledgments}

We thank study participants for providing information. Further, we acknowledge the support of Dr. Robert Busingye of the Department of Obstetrics and Gynecology, Mulago National Referral Hospital, Kampala.

\section{Authors' information}

MA holds a Master of Public Health (MPH), and currently an Assistant Lecturer at School of Health Sciences, Mountains of the Moon University, Fort Portal, Uganda. EM and VB both hold PhD in Public Health, and are Associate Professors working with the Department of Community Health, Mbarara University of Science and Technology, Uganda.

\section{References}

1. Reyburn H. New WHO guidelines for the treatment of malaria. BMJ. 2010;340:c2637.

2. Organization WH. World malaria report 2015: summary. 2016.

3. Nuwaha F. Factors influencing the use of bed nets in Mbarara municipality of Uganda. The American Journal of Tropical Medicine and Hygiene. 2001;65(6):877-82.

4. Mugisha F, Arinaitwe J. Sleeping arrangements and 
mosquito net use among under-fives: results from the Uganda Demographic and Health Survey. Malaria Journal. 2003;2(1):40.

5. Statistics UBo, Macro O. Uganda: Demographic and Health Survey, 2000-2001: Uganda Bureau of Statistics; 2001.

6. Statistics UBo. Uganda Malaria Indicator Survey. 201415. 2015.

7. Malaria RB. The Abuja Declaration and the Plan of Action: An Extract From the African Summit on Roll Back Malaria, Abuja, 25 April 2000. Geneva, Switzerland: Roll Back Malaria Partnership Secretariat, World Health Organization; 2003.

8. MoH U. Health sector strategic plan III 2010/112014/15. 2010.

9. Kish L. Survey sampling. 1965.

10. Nankinga Z, Muliira JK, Kalyango J, Nankabirwa J, Kiwuwa S, Njama-Meya D, et al. Factors associated with utilization of insecticide-treated nets in children seeking health care at a Ugandan hospital: perspective of child caregivers. Journal of Community Health. 2012;37(5):100614.

11. Miller JM, Korenromp EL, Nahlen BL, Steketee RW. Estimating the number of insecticide-treated nets required by African households to reach continent-wide malaria coverage targets. JAMA. 2007;297(20):2241-50.

12. Eisele TP, Keating J, Littrell M, Larsen D, Macintyre $\mathrm{K}$. Assessment of insecticide-treated bednet use among children and pregnant women across 15 countries using standardized national surveys. The American Journal of Tropical Medicine and Hygiene. 2009;80(2):209-14.

13. Bashinyora JB. Utilisation of insecticide treated nets in households with children under 5 years in muhorro sub county, kibaale district, uganda: Makerere University, Kampala; 2010.
14. Stevens ER, Aldridge A, Degbey Y, Pignandi A, Dorkenoo MA, Hugelen-Padin J. Evaluation of the 2011 long-lasting, insecticide-treated net distribution for universal coverage in Togo. Malaria Journal. 2013;12(162):10.1186.

15. Bennett A, Smith SJ, Yambasu S, Jambai A, Alemu W, Kabano A, et al. Household possession and use of insecticide-treated mosquito nets in Sierra Leone 6 months after a national mass-distribution campaign. PloS One. 2012;7(5):e37927.

16. Mujinja P, Makwaya C, Sauerhborn R. Gender and willingness to pay for insecticides treated bed nets in a poor rural area in Tanzania. East African Medical Journal. 2005;81(12):641-8.

17. Stewart T, Marchand R. Factors that affect the success and failure of Insecticide Treated Net Programs for malaria control in SE Asia and the Western Pacific. Geneva: World Health Organization. 2003:1-36.

18. Pulford J, Hetzel MW, Bryant M, Siba PM, Mueller I. Reported reasons for not using a mosquito net when one is available: a review of the published literature. Malaria Journal. 2011;10(83):10.1186.

19. Galvin K, Petford N, Ajose F, Davies D. An exploratory qualitative study on perceptions about mosquito bed nets in the Niger Delta: what are the barriers to sustained use? Journal of Multidisciplinary Healthcare. 2011;4:73-83.

20. Xu J-w, Liao Y-m, Liu H, Nie R-h, Havumaki J. Use of bed nets and factors that influence bed net use among Jinuo ethnic minority in Southern China. PloS One. 2014;9(7):e103780.

21. Chukwuocha UM, Dozie I, Onwuliri C, Ukaga C, Nwoke B, Nwankwo B, et al. Perceptions on the use of insecticide treated nets in parts of the Imo River Basin, Nigeria: implications for preventing malaria in pregnancy. African Journal of Reproductive Health. 2010;14(1). 